\title{
Dos colombianos en México: Rómulo Rozo y Porfirio Barba Jacob
}

\author{
Two Colombians in Mexico: \\ Rómulo Rozo and Porfirio Barba Jacob
}

\author{
Yezid David Sequeda Garrido \\ (D) 0000-0002-4715-5734 \\ Centro de Investigaciones y Estudios Superiores en \\ Antropología Social-Peninsular, México \\ yezu123@gmail.com
}

Resumen: Este artículo busca abordar la experiencia en México del escultor Rómulo Rozo y del poeta Porfirio Barba Jacob, dos artistas colombianos cuya estancia en este país marcó un importante momento en sus trayectorias artísticas y personales. Esta mirada se sitúa en el marco de relación e intercambio que México y Colombia mantuvieron durante la primera mitad del siglo xx. En este intercambio, las artes fueron espacios vinculantes en las agendas de relación de los gobiernos posrevolucionarios en México y de los gobiernos liberales en Colombia. Para la realización de este ejercicio fue precisa la consulta de documentación emanada del archivo de la Secretaría de Relaciones Exteriores de México y de la embajada de Colombia en México. También fue necesario consultar periódicos y revistas de circulación nacional en México y Colombia que otorgaron información sobre la presencia de estos dos personajes en territorio mexicano.

Palabras clave: México; Colombia; diplomacia cultural; Rómulo Rozo; Porfirio Barba Jacob.

Abstract: This article seeks to explore the experience in Mexico of sculptor Rómulo Rozo and poet Porfirio Barba Jacob, two Colombian artists whose stay in this country marked an important moment in their artistic and personal trajectories. It examines the framework of relations and exchange Mexico and Colombia maintained during the first half of the 20th century. In this 
exchange, the arts were binding spaces in the relationship agendas of the post revolutionary governments in Mexico and the liberal governments in Colombia. Undertaking this exercise required consulting documentation in the files of the Mexican Secretariat of Foreign Affairs and the Colombian Embassy in Mexico. It also entailed the analysis of national newspapers and journals in Mexico and Colombia with information on the presence of these two characters in Mexican territory.

Key words: Mexico; Colombia; cultural diplomacy; Romulo Rozo; Porfirio Barba Jacob.

Fecha de recepción: 15 de octubre de 2017 Fecha de aceptación: 20 de febrero de 2018

\begin{abstract}
A pesar de la distancia y de la dificultad de las comunicaciones, Colombia y México se buscan y se comprenden. Ramas de un árbol común que extiende sus frondas desde los márgenes del Bravo hasta la Tierra del Fuego en los términos australes, tenemos grandes semejanzas y parecidos problemas; perseguimos también el mismo ideal de engrandecimiento, de independencia y de bienestar.
\end{abstract}

Excélsior, 6 de julio de 1934.

Vagó, sensual y triste, por islas de su América; en un pinar de Honduras vigorizó el aliento; la tierra mexicana le dio su rebeldía, su libertad, su fuerza... Y era una llama al viento. Fragmento del poema "Futuro" (1923). En Barba Jacob (2011, p. 9).

\title{
PRESENTACIÓN
}

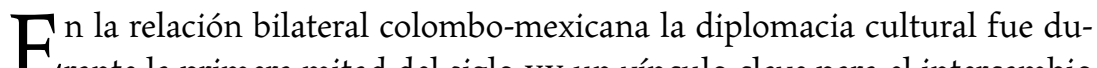
Erante la primera mitad del siglo xx un vínculo clave para el intercambio de conocimientos, la difusión artística y la búsqueda de enlaces institucio- 
nales. La cultura fue un espacio vinculante para ambas naciones, a partir de diversas formas de intercambio y de procesos de interacción por vías como el cine, la música y la actividad académica adelantada en universidades mexicanas y colombianas durante la primera mitad del siglo xx. La propaganda cultural -muy propia de los gobiernos posrevolucionarios- proyectó sobre Colombia la idea de un México matizado por las imágenes de su folclor, de sus reformas políticas y del realce dado a las expresiones populares, al indigenismo y a las artes, cuyos contenidos narraban vivencias de sectores otrora relegados del universo creativo. El muralismo mexicano, el cine de cantores y de historias heroicas -que en México marcó toda una época de apogeo para la producción nacional- y el repertorio musical de la posrevolución, fueron expresiones conocidas en Colombia de la mano de publicistas, intercambios académicos y canales de distribución internacional cercanos con la industria del entretenimiento. La presencia en las instancias diplomáticas mexicanas de personajes vinculados al mundo de las letras y la cultura, resultó favorable al interés por buscar mecanismos de cooperación académica y de mutuo conocimiento de las potencialidades y de la riqueza cultural presente en ambos territorios. De la mano de la ofensiva diplomática que buscó el reconocimiento internacional de los gobiernos posrevolucionarios, gran parte de la labor de los intelectuales y de los artistas se dedicó al establecimiento de vínculos culturales, que en el largo plazo dieron a la revolución una dimensión continental (Yankelevich, 2003, p. 18.). Tal propósito de difusión otorgó a la cultura mexicana un valor político susceptible de ser expuesto en distintos países latinoamericanos. El idioma, la historia, la literatura y las tradiciones sirvieron de puntos de encuentro con las intenciones gubernamentales (Picón-Salas, 1944, pp. 59-60). Isidro Fabela, Amado Nervo, Jesús Urueta recorrieron Sudamérica en el desempeño de distintas comisiones. También lo hicieron Luis G. Urbina, Luis Cabrera, Antonio Caso, José Vasconcelos, Genaro Fernández MacGregor, Julio Torri y Antonio Médiz Bolio (Yankelevich, 2003, p. 18).

Personajes como Palma Guillén -embajadora de México en Colombia para 1935- contribuyeron al establecimiento de este tipo de conexiones, al tiempo que su presencia resultó ser un factor relevante para el desarrollo de múltiples ideas de intercambio cultural (Palacios y Covarrubias, 2011, p. 304). Similar situación ocurrió con personajes como el embajador colombiano en México, Jorge Zalamea, y con la temprana vinculación de artistas como Rómulo Rozo en el ramo de la diplomacia. La visita de arquitectos, artesanos y bibliotecólogos mexicanos a Colombia, junto con la promoción 
del arte popular y las industrias típicas en ambos países, llevó a Guillén a buscar a la especialista en lacas María de Jesús Huerta y al vidriero Camilo Ávalos con el objeto de capacitar a artesanos colombianos. Igualmente, y con miras a emular experiencias en catalogación de libros, las gestiones de Juan B. Iguiniz, funcionario de la Biblioteca Nacional de México, brindó asesoría a la Biblioteca Nacional de Colombia. Por su parte la Academia Colombiana de la Historia nombró como miembros a varios de los integrantes de la Sociedad de Geografía y Estadística de México, entre quienes figuraron Juan Manuel Torrea, Rafael Heliodoro Valle e Ignacio León de la Barra (Palacios y Covarrubias, 2011, pp. 304-305.).

Con el propósito de hacer un intercambio cultural más fluido, en 1937 se trasladaron a México el ministro de Educación Jorge Zalamea y el poeta Germán Pardo García; el primero con la intención de participar en la Conferencia Panamericana sobre Educación y el segundo con planes de realizar estudios sobre poesía latinoamericana. ${ }^{1}$ Durante los años cuarenta la publicación de diversos libros en México fue comentada continuamente en los informes consulares con el fin de dar cuenta sobre los acontecimientos literarios y la influencia de escritores españoles y estadunidenses en el ámbito intelectual. Listados con títulos de escritos recientes como los de Rafael Heliodoro Valle, ensayos filosóficos, boletines noticiosos de periódicos como El Universal y novedades literarias como las del cuarto tomo del Centenario de la imprenta en México de la autoría de don Francisco Gamoneda, formaron parte de estas reseñas que, desde México, enviaba Jorge Zawadzky al Ministerio de Relaciones Exteriores, dirigido en Colombia por Luis López de Mesa. ${ }^{2}$

Estos informes mencionaban las actividades culturales mexicanas, al lado de las gestiones presidenciales, así como reportaban la situación económica y las relaciones internacionales, en un contexto matizado por las tensiones políticas internacionales. En la retórica oficial, la riqueza cultural, el pasado compartido y los ideales de unidad latinoamericana, fueron frecuentemente traídos a colación como ejes claves para fortalecer los vínculos oficiales, estrechar las alianzas políticas entre México y Colombia y así dar fomento a valores de una identidad imaginaria, por la vía del cultivo de las ciencias,

1 "Noticia de viaje", El Siglo, 2 de agosto de 1937.

${ }^{2}$ Fondo Cancillerías Organismos Internacionales. Boletín de Noticias, núm. 73, 8 de enero de 1941. Archivo General de la Nación Colombia (en adelante AGNC), Colombia. 
las artes y la cooperación. ${ }^{3}$ Igualmente, los eventos académicos en México posibilitaron la visita y el traslado de estudiantes y profesores colombianos. La afluencia de estudiantes colombianos a México fue en aumento durante los años cuarenta, ya que contaba con la intervención de las instancias diplomáticas a la hora de facilitar trámites y emitir documentación pertinente. ${ }^{4}$ Las exposiciones de pintores, escultores, fotógrafos y artistas colombianos en la Ciudad de México dieron a conocer los trabajos y las creaciones de quienes se encontraban radicados en este país, bien fuese en calidad de estudiantes, trabajadores o personas vinculadas al medio artístico. Creaciones de Juan Sanz de Santamaría, esculturas y óleos de Luis Alberto Acuña, tallas en piedra de Rómulo Rozo, figuras en madera de Julio Abril y fotografías de Leo Matiz fueron parte de esta oferta artística. ${ }^{5}$

En este espacio de interconexión cultural colombo-mexicano se resalta la presencia del escultor Rómulo Rozo y del poeta Porfirio Barba Jacob, quienes a partir de sus saberes dieron importantes aportes a la poesía y al arte latinoamericano, visibles en los contenidos de sus obras y en la influencia ejercida en el ámbito literario y artístico de las medianías del siglo xx.

Lo que este artículo persigue es acercarse a la estancia de estos dos artistas a partir de una mirada que aborde sus experiencias y sus cercanías con personajes del ámbito político y artístico del México de los años treinta y cuarenta. Para la realización de este ejercicio fue preciso consultar archivos diplomáticos en México y Colombia, periódicos y revistas de circulación nacional, que junto con la consulta de bibliografía especializada permitieron conocer aspectos relevantes de la época y del momento histórico transitado por estos dos personajes. Dos momentos ligados a Rómulo Rozo y a Porfirio Barba Jacob integran esta mirada construida con un enfoque histórico, encaminado a visualizar su tránsito por México, como parte de un intercambio cultural de mayor amplitud sostenido por los dos países durante la primera mitad del siglo $\mathrm{xx}$.

3 "Presentación de credenciales de Miguel Ángel Menéndez como embajador de México en Colombia”, El Tiempo, 7 de febrero de 1943, pp. 1 y 7.

${ }^{4}$ Fondo Cancillerías Organismos Internacionales. Informe de Jorge Zalamea, 10 de diciembre de 1943, AGNC, Colombia.

${ }^{5}$ Fondo Cancillerías Organismos Internacionales, caja 638, carpeta 44, Boletín de Noticias, núm. 90, 23 de julio de 1943, AGNC, Colombia. 


\section{RÓMULO ROZO Y EL ARTE MONUMENTAL MEXICANO}

La figura del boyacense Rómulo Rozo Peña ocupa un importante lugar en la historia del arte colombiano. Sus aportes e influencias también fueron de gran valor en ciudades mexicanas como Mérida, lugar en el que vivió desde finales de los años treinta y hasta su muerte ocurrida en 1964. Desde finales de la década de los veinte los progresos artísticos de Rómulo Rozo en el extranjero aparecieron en la prensa colombiana, que publicaba comentarios y cartas de críticos franceses sobre aspectos de su formación artística durante su estancia en París. ${ }^{6}$ Esta experiencia de Rozo en París marcó para el arte colombiano un importante momento de apertura hacia el americanismo y hacia la exploración de las mitologías y de la iconografía del arte indígena prehispánico (Suárez, 2016, p. 3).

Para este periodo de su formación, la crítica francesa reconocía en las obras de Rozo una profunda originalidad, una gran capacidad para manejar la monocromía en materiales como el granito, mientras hablaban de su firmeza creativa y de su fuerza imaginativa. ${ }^{7}$ Durante este temprano paso por Francia, Rómulo Rozo tuvo la oportunidad de exponer en el Salón de Artistas Franceses en París algunas de sus esculturas elaboradas en granito y otros materiales. Los comentarios de críticos de arte como Gastón de Pawlosky y Marcel Sauvage fueron reproducidos en la revista colombiana Cromos exaltando los logros del artista. ${ }^{8}$ Este periodo formativo le permitió recibir influencias de Rodin y de otras tendencias escultóricas en boga.

Su obra Bachué diosa generatriz de los indios chibchas de 1925 fue de gran trascendencia para el arte colombiano al expresar una intensión que rompió con los cánones predominantes en la producción artística local y en la generación del centenario. La Bachué se convirtió en un referente de la modernidad artística y en la inspiración para que escritores colombianos como Darío Achury Valenzuela, Darío Samper y Tulio Gonzales, publicaran en el periódico El Tiempo de Bogotá un manifiesto que buscaba recalcar por la vía de las artes los valores y la identidad propia (Suárez, 2016, p. 4). El "bachuismo" recalcó en el papel social del arte y en la responsabilidad de sus cultivadores

${ }^{6}$ M. A. Dupois, "Continúan los triunfos de un artista colombiano", El Tiempo, 4 de junio de 1928 , p. 5.

7 "Arte Nacional", revista Cromos, 28 de julio de 1928.

8 "Arte Nacional", revista Cromos, 28 de julio de 1928. 
por el realce de la cultura latinoamericana y pese a su corta existencia, que no pasó de un par de escritos publicados en El Tiempo de Bogotá, sí fue clara la influencia que la Bachué de Rozo tuvo entre los artistas plásticos de la época (Padilla, 2013, p. 19). De acuerdo con el profesor de arte Álvaro Medina, Bachué respondía al anhelo de hallarle a la expresión cultural de Iberoamérica una poética que expresara la idiosincrasia de estos pueblos, distintos de los europeos en su recorrido histórico y en su experiencia vital (Medina, 2013, p. 27). El reconocimiento que Bachué otorgó a Rozo sirvió para que el gobierno colombiano le encargara la organización del Pabellón de Colombia en la Exposición Iberoamericana de Sevilla de 1929, en la que esta obra ocupó un lugar de importancia (Padilla, 2013, p. 48).

Su llegada a México en 1931 marcó quizá uno de los momentos más importantes de su formación académica, su vida familiar y su producción artística. Recién llegado, Rozo fue agregado cultural de la embajada colombiana acreditada en México y así logró vincularse con círculos artísticos y académicos de la capital a principios de los años treinta. Durante esta experiencia que se remontó por un periodo de casi cinco años, de acuerdo con un artículo de Gómez Jaramillo, Rómulo Rozo pudo exponer en el Salón Permanente de Pintura. También fue profesor en la Academia de San Carlos y en algunas escuelas de talla directa (Charlot, 1985, pp. 59-75). De este periodo datan obras escultóricas como Pensamiento (1931), Anunciación (1931), Raza (1932), El Beso (1932), La Noche (1932), Añoranza (1932), India (1933), Maternidad (1934), La Mestiza (1936), entre otras. En la obra de Rómulo Rozo desempeñaron un papel relevante las influencias recibidas por las vanguardias de Francia y España, países claves en su formación y en la de algunos artistas partícipes del renacimiento artístico mexicano.

Sin embargo, fue en Yucatán donde realizó sus mayores aportes artísticos. Hacia 1936, estando en la ciudad de Mérida, Rómulo Rozo expuso algunas de sus obras escultóricas y diversos retratos, así como sus fotografías de arte prehispánico, algunas de ellas, pertenecientes a la cultura San Agustín asentada en el sur de Colombia. En el Museo Arqueológico e Histórico de Yucatán y junto a una exposición de la Institución Carnegie de Washington, Rozo pudo mostrar este trabajo, hablar de sus experiencias y de sus impresiones de la península, su historia, su cultura y sus habitantes, con un lenguaje poético matizado por sus emociones. Al escribir sobre Mérida y dejando entrever su sensibilidad personal Rozo afirmaba en un escrito reproducido en Colombia por el periódico El Tiempo: 
Mérida, niña preciosa, mestiza dominguera. Qué alegre y limpia eres, como me agrada tu tostada tez. Parece que la naturaleza te formó del barro, cieno de tus senderos húmedos de tus campos fecundos. Tu boca parece que musita una canción o desgrana una plegaria; tus labios de tibieza tersos, balancean unas cornisuras traviesas, húmedas de sonrisas rituales. Como tú, todas las mujeres, con su andar graciosamente original, han tejido una red de armonías en mi vida. Tu rostro, armoniosamente hoyueladito, es como la miel de tus panales que untan de alegría y de emoción a quien las mira. Tus ojos negros y tu mirada son una promesa que predisponen al viajero a la amistad, al afecto y al amor. Tu extraordinario espíritu hace de tu vida una figura digna de toda veneración y en tu mirar parecen aletear todas las ternuras. Tu eres la paz, la esperanza y el inmenso valor de tus varones. ${ }^{9}$

De acuerdo con el escritor y periodista colombiano Yesid Contreras, Rómulo Rozo recorrió en 1937 la península de Yucatán como miembro de la Expedición Científica Mexicana del Sureste. ${ }^{10}$ En esta ocasión, realizó dos obras decorativas arquitectónicas en Chetumal: una en la Escuela Belisario Domínguez -hoy convertida en Centro de Bellas Artes- y otra en el hospital Morelos. ${ }^{11}$ En la Belisario Domínguez talló ocho columnas en bajo relieve con figuras indígenas mayas, esculpió en el auditorio al aire libre una danza que incluía campesinos chicleros, mujeres con atuendos autóctonos y escudos nacionales, mientras que en el hospital Morelos esculpió un friso alusivo a la Fuente de la Salud, acompañada de figuras propias de las culturas mesoamericanas. ${ }^{12}$

Su estancia en Mérida le permitió entablar amistad con el escritor y diplomático yucateco Miguel Ángel Menéndez, quien valoraba particularmente su obra y su estilo americanista, pensando que se trataba de importantes momentos para el arte nacional y latinoamericano. ${ }^{13}$ Las opiniones de Menéndez dejaban entrever sus simpatías por el artista y el conocimiento de su trayectoria, en una época en la que dicho escritor yucateco se desempeñaba

9 "Reportaje", El Tiempo, 15 de marzo de 1936, p. 7.

10 "Lecturas dominicales", Escrito publicado con ocasión de la conmemoración de los 50 años de su muerte, El Tiempo, 30 de julio de 2014.

11 "Lecturas dominicales", El Tiempo, 30 de julio de 2014.

12 "Lecturas dominicales", El Tiempo, 30 de julio de 2014.

${ }^{13}$ Luis E. Osorio, “Con el embajador Menéndez. Evocación de México”, El Tiempo, 7 de marzo de 1943, p. 7. 
como embajador de México en Colombia y durante la cual esporádicamente expresaba ante la prensa sus ideas de la cultura y el arte mexicanos.

Su trabajo en México reflejó la influencia recibida por las nuevas lecturas en torno al arte prehispánico, a su riqueza estética y a su revaloración conceptual. ${ }^{14}$ Ignacio Gómez Jaramillo publicó sus apreciaciones sobre la vida y obra de Rozo en un momento en que el artista ya completaba cinco años esculpiendo el Monumento a la Patria Mexicana en la ciudad de Mérida, inaugurado muchos años después por el presidente Adolfo Ruiz Cortines durante el mandato regional de Víctor Mena Palomo. Esta obra fue iniciada el 7 de marzo de 1945 y fue inaugurada el 23 de abril de 1956. En su construcción intervinieron los arquitectos Manuel y Max Amábilis, el maestro de obras Víctor Nazario Ojeda y contó con el apoyo financiero del gobierno del estado, la Secretaría de Educación Pública encabezada entonces por Jaime Torres Bodet, el Instituto Nacional de Bellas Artes y la Escuela de Pintura y Escultura (Rozo, 1956, p. 17).

Rescatando olvidadas técnicas yucatecas de labrado, tallado en piedra fina y trabajando con la luz y las sombras del terreno sobre el cual se levantó el monumento, se buscó la manera de representar a la patria en la figura de una mujer vestida con traje típico, sandalias y decorada con elementos alusivos a la tierra, al dios Kukulcán y a diversos símbolos de la filosofía maya (Rozo, 1956, p. 27). Para conocedores de la trayectoria artística de Rozo, este trabajo fue su obra más ambiciosa y marcó un regreso al arte profuso y ornamentado de sus inicios, mientras dio cabida a viejos anhelos por trabajar en obras escultóricas de tipo arquitectónico manteniéndose fiel a su ideal prehispánico (Medina, 1999, p. 34).

De acuerdo con el historiador Marco Díaz Güemez (2014, pp. 329-335), esta obra es parte de una serie de monumentos y construcciones arquitectónicas que en Yucatán expresaron intenciones políticas e identitarias, ligadas a ideas socialistas y a criterios de renovación urbana, pensadas por la clase dirigente yucateca, durante la primera mitad del siglo xx. Localizado hoy por hoy en una de las avenidas más importantes de la ciudad de Mérida, este monumento realza valores regionales, mientras da cuenta de interesantes episodios de la historia de Yucatán y de sus símbolos más queridos. Rómulo Rozo fue un artista muy comprometido con su tiempo y con el arte que logró

${ }^{14}$ Ignacio Gómez Jaramillo, "Reportaje”, El Tiempo, 25 de junio de 1950, suplemento literario, p. 1 . 
cultivar a lo largo de su vida. Sus aportes y creaciones forman parte de un interesante capítulo de la historia del arte latinoamericano, en el que la valoración de lo propio ocupó un lugar de primer orden.

Aunque parezca un lugar común imperdonable, Bachué diosa generatriz de los indios chibcha de 1925 junto al Monumento a la Patria de 1956, señalaron en la trayectoria artística de Rozo y en el ambiente cultural de México y Colombia dos momentos claves. Para Colombia, marcó una ruptura con la tradición imperante y con las miradas europeizantes, mientras difundió la idea de construir un arte local, misma que permeó la producción de otros artistas nacionales. En México expresó de manera clara el carácter de una época, las intenciones por acoger el legado prehispánico y el interés por exaltar la participación del pueblo mexicano en la construcción de un nuevo sentido de la historia y de los vínculos nacionales. Edificada en medio del auge del panamericanismo y de los años posteriores a la segunda guerra mundial, la obra de Rómulo Rozo nutrió el arte latinoamericano y plasmó en muchos de sus trabajos la visión de un mundo recordado en la grandeza de tiempos remotos. De modo similar a lo ocurrido con el poeta Barba Jacob, Rómulo Rozo logró influir en la sociedad y en el arte de su tiempo, por medio de su trabajo y de los vínculos que se gestaron a lo largo de su permanencia en México.

\section{PORFIRIO BARBA JACOB}

Porfirio Barba Jacob tuvo una particular importancia en el quehacer poético latinoamericano justo en los momentos de auge del panamericanismo. La relación de Barba Jacob con México, dada su prolongada estancia y el desarrollo de múltiples actividades en su suelo, fue determinante en su vida personal y en su creación artística. La profundidad de su lírica y el sello propio que sus vivencias aportaron a sus creaciones lo convirtieron en un poeta que expresaba dolores, alegrías, sentimientos y voces inquietantes muy propias de la condición humana (Bloy, 1946, p. 16). Asociado al modernismo y a los poetas malditos, la obra de Barba Jacob -buena parte de ella escrita y editada en México- otorga valiosos aportes a la poesía colombiana. La popularidad que alcanzaron algunos de sus poemas y el carácter provinciano que los acompañó le dieron, de acuerdo con la escritora colombiana Piedad Bonnett, un lugar entre los mejores poetas del siglo xx (Bonnett, 1992, p. 184). 
Lo itinerante de su existencia y lo problemático que resultó su relación con las drogas y el alcohol, fueron algunos de los episodios que rodearon su vida personal, como cuenta Cobo (2003):

No le demos más vueltas: Barba no era un visionario que previó su destino. Era, simplemente al contrario de lo que él quería hacernos creer, un hombre que por reacción a su medio campesino, en todo sentido, a través del homosexualismo, las drogas y el exilio, buscó asumir una imagen de poeta maldito. Escribió los poemas para volverse esos poemas. La poesía lo amparaba así de sus desgracias personales, en un ámbito intemporal -esa sucesión de desterrados, de parias, de Verlaines que él invoca. Pero lo grave es que la poesía también traiciona, haciendo que la cotidiana y afligente vida diaria que Barba llevaba no alcanzara a volverse palabra convincente (p. 140).

Cercano a poetas mexicanos como Enrique González Martínez -conocedor de su trabajo artístico y quien acompañó al poeta durante sus últimos días en la capital mexicana- la estancia de Barba Jacob en México transcurre entre periódicos, revistas, cantinas y garajes de El Paso, Texas, y de Chihuahua, afrontando necesidades y carencias económicas. El ejercicio periodístico de Barba Jacob en México expresó su ideario político, su rechazo por el totalitarismo y una gran lucidez a la hora de escribir (Barba Jacob, 2009, p. 14). Reportajes y artículos sobre temas variados publicados en periódicos y revistas -algunos de corta duración, como ya se ha dicho- reflejaron a un escritor moderno, polifacético, capaz de narrar lo que veía y de encarar en sus contenidos el carácter de una época (Barba Jacob, 2009, p. 15).

En esta faceta que cubrió la mayor parte de su estancia en México, el poeta expresó sus posturas ante personajes y acontecimientos latinoamericanos que ocuparon la atención de sus publicaciones en los periódicos a los que fue cercano. Las ideas de integración latinoamericana presentes en los escritos que Barba Jacob publicó en la prensa mexicana, colocaron en más de una ocasión a la figura de Simón Bolívar como uno de los personajes principales y protagónicos de la historia continental (Bejarano, 2010, p. 64). Las alusiones a Bolívar por parte de Barba Jacob, además de exaltar su papel protagónico en la historia, se suman a una intensión de unidad hispanoamericana muy propia del momento (Bejarano, 2010, p. 71.).

Algunas de las cartas de su correspondencia personal, recopilada muchos años después de su muerte por el escritor colombiano Fernando Vallejo, 
dejan entrever sus contactos con múltiples personajes del ámbito diplomático, político y literario. Figuras como Carlos Pellicer -quien años después ayudaría a repatriar sus despojos mortales a tierra colombiana- aparecen en las últimas cartas que en vida escribió el poeta, en un momento en que su estado de salud motivó el pedido de ayuda del embajador Jorge Zawadzky al gobierno colombiano, con el fin de ayudarle con un tratamiento clínico y con unos recursos pedidos al Congreso nacional. ${ }^{15}$

En el ámbito diplomático el poeta se vinculó a personajes como el propio embajador Jorge Zawadzky, el ministro colombiano Luis López de Meza, los mexicanos Alfonso Reyes y Jaime Torres Bodet. En una carta dirigida a Luis López de Meza, Barba Jacob expresaba:

No podría decir que tenga cabal salud, pero gozo de algo así como el equilibrio inestable, que a los 54 años no deja de ser una santa conquista. Trabajo en un periódico rico e importante, donde me quieren y me tratan bien. Soy por lo menos el galeote agradecido. Todas las mañanas sobre los problemas sociales, políticos, económicos e intelectuales de México y aún del mundo, sobre leyes y decretos, sobre crímenes, sobre todo cuanto hay. A veces me duele profundamente considerar que mis tremulantes energías, que debieran estar dedicadas a Colombia, me dispersen hacia otros rumbos. Me consuela el pensamiento de que no elegí el lugar de mi residencia; por otra parte, amo a México y pienso que servir a México es también servir a mi patria. ${ }^{16}$

Hacia finales de 1941, y en un momento en que sus padecimientos físicos lo tenían postrado en un cuarto del hotel Sevilla, concedió una entrevista al poeta veracruzano Neftalí Beltrán en la que habló de sus vivencias en México. Esta entrevista fue publicada en el diario El Tiempo en enero de 1942. En compañía del poeta colombiano Germán Pardo García, establecido en México a partir de los años treinta, Barba Jacob recordó con nostalgia sus años de infancia y de su temprana cercanía con la poesía a través de la lectura de

${ }^{15}$ Carta de Barba Jacob a Jorge Zawadzky, México, 9 de noviembre de 1941. En Vallejo (1992, pp. 248-250).

${ }_{16}$ Carta a Luis López de Meza, México, 12 de junio de 1937. En Vallejo (1992, pp. 195-198). En esta misma carta el poeta expresa al entonces ministro de Instrucción Pública sus intenciones por fundar a futuro una revista bajo el nombre México-Colombia, con la finalidad de abordar temas de mutuo interés y de dar a conocer obras poéticas y literarias de escritores de ambos países. 
poemas de Guillermo Valencia, Luis G. Urbina y José Asunción Silva cuando tenía quince años de edad.

También habló de sus padres, de sus abuelos y de ese entorno rural en el que creció y vivió sus primeros años. Mientras recordaba aspectos de su trayectoria, Barba Jacob se refirió a su relación con la poesía, a la que consideraba un aspecto clave y vital en su existencia y de la que nunca esperó reconocimientos. Al hablar de la poesía Barba Jacob señaló:

He sacado la poesía de mí mismo, y ha sido, durante toda mi vida, un ejercicio desinteresado no solo en cuanto a lo económico, sino que nunca me he preocupado siquiera de hacerme publicidad alguna. El hecho de haber llegado a los cincuenta años sin publicar un libro, lo demuestra. Y es que la poesía ha sido para mí la mejor recompensa. Recompensa de haber nacido de tener que morir, de sufrir y de encontrarme dentro del mundo [...] y sin embargo la poesía ha sido para mí la presea, la corona de todos mis esfuerzos, de todas mis luchas en la vida. Usted lo ve. Estoy pobre, enfermo, y aun así, si en mi mano estuviera el poder volver a nacer y cambiar el panorama de mi vida no lo haría. ${ }^{17}$

Barba Jacob recordó su primer poema titulado "La tristeza del camino" en el que se reconocía como un católico por elegancia. Recordando su llegada a México decía:

He vagado por aquí y por allá... Llegué a México en 1907, sin dinero y como un campesino asustado. Recuerdo que me causó pavor la metrópoli, un miedo extraño. Fui entonces a vivir a Monterrey y allí me hice periodista. México es un país extraordinario, me gusta muchísimo, aunque claro, tengo siempre la nostalgia de Colombia. Sigo siendo muy antioqueño en mi carácter, y hombre de ideas universales. Esto es, un hombre que, al fin y al cabo es el elemento poético por excelencia, todo elemento estético reside allí, porque la poesía debe ser humana y el hombre ha sido y sigue siendo valor estético en todas las épocas. ${ }^{18}$

Esta entrevista publicada por Germán Pardo García en la revista Noticia de Colombia dirigida y difundida por este escritor en México, fue la última concedida por Barba Jacob en vida y pudo ser conocida en Colombia gracias a

17 Neftalí Beltrán, "Reportaje”, El Tiempo, 21 de enero de 1942, p. 2.

${ }^{18}$ Neftalí Beltrán, "Reportaje”, El Tiempo, 21 de enero de 1942, p. 2. 
la reproducción hecha por El Tiempo, días después de conocerse la noticia de su muerte. Una fotografía de Barba Jacob acostado en una cama acompañaba la entrevista, al lado de escritos hechos por personas cercanas al ámbito poético y literario nacional. En esta fase terminal de su vida, recibió la confesión y sus últimos sacramentos de parte del sacerdote y literato mexicano Gabriel Méndez Plancarte. Germán Pardo García, narró para la prensa:

"Estoy en la paz de Dios" nos dijo al día siguiente. Y nosotros, que nunca antes a través de nuestra larga amistad, le oímos hablar de la idea de Dios concretada en los credos y ritos católicos, aceptamos con reverente humildad la transformación de este espíritu que descendió hasta los más obscuros senos de las pasiones, en donde toda teológica y directriz se dispersa ante los ciegos empujes de las fuerzas negativas, pero se alzó de allí transfigurado y se doblegó ante el deshonor del Gólgota. ${ }^{19}$

La muerte de Barba Jacob ocurrida en este hotel de la ciudad de México hacia los primeros días de enero de 1942, fue comentada ampliamente en la prensa nacional por autores colombianos y personas cercanas al artista, quienes, a manera de homenaje, abordaron diversos aspectos de su vida y de su trayectoria artística. El escritor y diplomático Luis Eduardo Nieto Caballero lo consideró como un poeta con grandes influencias de Paul Verlaine: al describirlo así: "Verdugo de su honor, actor de sus tragedias, árbitro de su torpe destino, como lo cantó él mismo, sentía que había vivido con alma, con sangre, con nervios, con músculos y que iba al olvido, sin que en ello hallara alcanzada la satisfacción, sino la indiferencia." ${ }^{20}$

Para el también poeta y escritor Darío Samper, la obra de Barba Jacob ocupaba un importante lugar en el mundo de la literatura colombiana y en el escenario de la América Hispana, que fácilmente podía compartir con escritores como José Asunción Silva y Rubén Darío. ${ }^{21}$ Similar opinión expresaba Andrés Holguín, para quien la poesía del antioqueño era un largo viaje en busca del hombre eterno y de aquello inmutable, que a través de sí mismo

${ }^{19}$ Neftalí Beltrán, “Porfirio Barba Jacob”, El Tiempo, 16 de enero de 1942, p. 2.

${ }^{20}$ Luis Eduardo Nieto Caballero, "Porfirio Barba Jacob", El Tiempo, 16 de enero de 1942, p. 2.

${ }^{21}$ Darío Samper, "Notas sobre la poesía de Porfirio Barba Jacob", El Tiempo, 18 de enero de 1942 , p. 15. 
exploraba y transmitía en sus poemas. ${ }^{22}$ Para el escritor Eduardo Carranza, la grandeza de su obra era un aporte valioso a la poesía castellana, que junto a su estilo modernista y melancólico, reflejaron aspectos de su vida, de su signo fatal y de su tránsito por el mundo.

En estos escritos, aparece como lugar común la metáfora oscura de la vida del poeta, que de manera recurrente fue utilizada por los amigos y conocedores de su obra, como un correlato de sus tragedias personales, de sus soledades y de sus andanzas entre cambios, reacomodos y penurias materiales que le acompañaron durante su temprana vida campesina en Santa Rosa de Osos. Además de los ya mencionados, escritores y periodistas como Aquilino Villegas, Horacio Franco, Juan Cristóbal Martínez, Roque Casas y Guillermo Manrique Terán, también se encargaron de publicar sus percepciones en torno a la vida y obra del poeta colombiano, junto a la divulgación de poemas como "Canción de la vida profunda", "El son del viento", "La canción de la noche diamantina", "El solar de los lulos de oro" y "La caída del telón".

El poeta colombiano Carlos Martín (1942) comentó, por ejemplo:

El amor es virtud de intuición: Barba Jacob amó este mundo caótico, en formación, y nos dio en el cristal de su canto, herido por todas las pasiones que nos son características, el reflejo fiel del rostro de este suelo rugoso, tostado por el sol y golpeado por los vientos fluviales y marítimos; de este gran cuerpo extendido, moreno y frutal de América Hispana, que respira, que tiene hambre, que tiene sed, que recobra fuerzas o languidece y que sostiene al hombre, le nutre, le abreva y le guarda hasta el aniquilamiento de su fugaz hechura de lágrimas y arcilla (p. 153).

Un homenaje a la memoria del poeta antioqueño fue organizado por la Universidad Autónoma de México en marzo de 1942. Al citado homenaje asistieron el rector Mario de la Cueva, el embajador Jorge Zawadzky, el escritor Alfonso Junco y una nutrida audiencia que se congregó en el anfiteatro Bolívar.

Las palabras de Junco recordaron aspectos de la vida de Barba Jacob, entre las que destacó su experiencia en la formación de revistas como la $R e-$ vista Contemporánea, su trabajo en periódicos, además de mencionar algunos

${ }^{22}$ Andrés Holguín, "Porfirio Barba Jacob en la poesía colombiana", El Tiempo, 18 de enero de 1942 , p. 15. 
de sus recuerdos personales en Monterrey donde convivió con el poeta colombiano. ${ }^{23}$ En uno de los apartados de su discurso, Alfonso Junco manifestó:

Recién venido el colombiano a México, llegó a mi natal Monterrey, por 1908, cuando era yo un chico de doce años y él rondaba los veinticinco. Tarde a tarde visitaba mi casa, aquella casona patriarcal, abierta, alborozada, rumorosa y deleitaba en la armonía hogareña. Él paladeaba el provinciano chocolate, nosotros la maravilla de su plática.

Encariñose en Monterrey, que obró el milagro de cautivar no pocos años a aquel espíritu errabundo, hasta que un día se acordó de sus palabras mágicas, de las que él llamaba sus dos alas; "me voy".

Y se fue. ${ }^{24}$

Tras cuatro años del fallecimiento de Porfirio Barba Jacob y como una forma de rendir tributo a su memoria, el traslado de sus cenizas de México a tierras colombianas y su instalación en el Cementerio Universal de Medellín, estuvo rodeado de actos públicos en los que participaron escritores, funcionarios de ambos gobiernos y autoridades locales. Personajes como Germán Arciniegas - quien para esa época fungía como ministro de Educación-, Gilberto Owen, los poetas León de Greiff y Ciro Medina, el escritor Carlos Pellicer y personalidades del ámbito político y académico, estuvieron presentes en los homenajes que organizó la Universidad de Antioquia y el gobierno municipal. El diplomático Francisco Castillo Nájera también recordó la estancia de Barba Jacob en suelo mexicano. ${ }^{25}$

Pero tal vez el homenaje de Carlos Pellicer, quien recordó su paso por Colombia y su amistad con el poeta, fue el que mayormente conmovió a los asistentes al Paraninfo de la Universidad de Antioquia. ${ }^{26}$ Este homenaje en el que fue frecuente el recuerdo de vivencias, versos y poemas, dio también cuenta del aprecio que muchos escritores colombianos tenían por el mexicano Carlos Pellicer. Destacan entre ellos: los hermanos de Greiff: Otto y León, Darío Samper, Luis Eduardo Nieto Caballero, Germán Arciniegas y Daniel Arango, quien lo recordó días después en una de sus columnas en el periódi-

${ }^{23}$ Fondo Cancillerías. Informe de Embajada. 20 de marzo de 1942. AGNC, Colombia.

${ }^{24}$ Fondo Cancillerías. Informe de Embajada. 20 de marzo de 1942. AGNC, Colombia.

25 "Noticia", El Tiempo, 14 de enero de 1946. p. 6.

${ }^{26}$ Germán Arciniegas, "Ante los restos de Barba Jacob”, El Tiempo, 20 de enero de 1946. suplemento, p. 2. 
co El Tiempo junto a la publicación de tres poemas: "Estudio", "La danza" y "Horas de junio". ${ }^{27}$

Paisajes conocidos, vivencias a ratos alegres, a ratos entristecidas y de vez en cuando cargadas de una profunda nostalgia, quedaron plasmadas en los versos de este recordado poeta colombiano. El legado de Porfirio Barba Jacob para la poesía colombiana es amplio y está cargado de experiencias que enriquecieron el repertorio latinoamericano. Con un estilo distintivo y con versos influenciados por la vanguardia de su época, logró el reconocimiento de su obra en otros países de la región, convirtiéndose en referente de las letras colombianas de la primera mitad del siglo xx. Sus cercanías con México quedan como un interesante momento en la relación bilateral y sus poemas quedan como el reflejo de sus mundos, sus percepciones y su talento creativo. En un plano de mayor amplitud, los vínculos culturales colombo-mexicanos hicieron presencia durante el panamericanismo como un componente que dinamizó la relación bilateral y forjó en la figura de artistas, cineastas, poetas, músicos y escritores, un interesante espacio de intercambios. Este dinamismo hizo posible el conocimiento de diversos tópicos de la cultura nacional, a los que la actividad diplomática, en ocasiones, sirvió como intermediario y canal de cercanía.

\section{A MODO DE CONCLUSIONES}

La intervención pública en el ámbito de la cultura estuvo mediada en México y Colombia durante los años treinta y cuarenta del siglo xx por una política encaminada a reconocer valores y expresiones populares. Pensar la política cultural como una "acción dirigida", que influía sobre la sociedad a partir de la intervención estatal en las artes, en la educación y en el fomento del folclor, fue un factor que dinamizó patrocinios, mecenazgos, formas de difusión y políticas públicas, que oxigenaron la relación de algunos artistas e intelectuales con el aparato estatal. Las políticas educativas y las nuevas lecturas en torno a la cultura popular se convirtieron en un proceso vinculante para ambas naciones durante los años treinta y cuarenta, en medio de planes y pautas de reorganización curricular que dieron cabida al realce del folclor nacional

${ }^{27}$ Germán Arciniegas, “Ante los restos de Barba Jacob”, El Tiempo, 20 de enero de 1946, suplemento, p. 2. 
y a la promoción de valores que resignificaban y creaban nuevas conciencias en torno al nacionalismo y a la pertenencia regional. La cultura entendida a partir de la multiplicidad de expresiones y manifestaciones que definen los rasgos de una sociedad en particular fue un espacio vinculante para ambas naciones, bajo la óptica de sus intercambios y procesos de interacción, por vías como el cine, la música y la actividad académica adelantada en universidades mexicanas y colombianas.

La estancia de artistas colombianos en territorio mexicano ejerció en su formación y en sus producciones una notable influencia, derivada de las escuelas y de las tendencias en apogeo en el universo de las artes y la literatura. Barba Jacob y Rómulo Rozo pueden ser considerados como miembros de una temprana generación de artistas e intelectuales colombianos que vieron en México un lugar apto para el florecimiento de su arte y de sus formas de expresión, mucho antes de la llegada de importantes escritores, poetas y pintores, quienes en décadas posteriores establecieron en este país sus lugares de estudio y de estancia. Esta ligera mirada sobre la experiencia mexicana de dos artistas colombianos, permitió conocer el influjo de los intercambios que México y Colombia mantuvieron durante la primera mitad del siglo xx y en los que el entorno cultural fue influido por las miradas que la posrevolución otorgó a las artes y a las expresiones populares como herramientas útiles para la difusión de un proyecto político de mayor amplitud.

\section{LISTA DE REFERENCIAS}

Barba Jacob, P. (2009). Escritos mexicanos (invest., selec. y pról. de E. García Aguilar). Bogotá: FCE.

Bejarano, A. (2010). El rastro en la arena: Barba Jacob, lector de Bolívar. Relectura de sus Escritos mexicanos (The trail in the sand: Barba Jacob reader of Bolivar. Reading of his Escritos mexicanos). Estudios de Literatura Colombiana, 26, 61-73. Recuperado de https://aprendeenlinea.udea.edu.co/revistas/index.php/elc/article/ view/9868

Bloy, L. (1946). Porfirio Barba Jacob. Revista de las Indias, 27(86).

Bonnet, P. (1992). Porfirio Barba Jacob. Gran Enciclopedia de Colombia Temática (t. 4, pp. 179-184). Bogotá: Círculo de Lectores.

Charlot, J. (1985). El renacimiento del muralismo mexicano, 1920-1925. México: Domés. 
Cobo, J. (2003). Historia de la poesía colombiana siglo xx. De José Asunción Silva a Raúl Gómez Jattin. Bogotá: Villegas Editores.

Díaz, M. (2014). El arte monumental del socialismo yucateco (1918-1956). (Tesis de doctorado). ciesas-Peninsular, México.

Martín, C. (1942). Porfirio Barba Jacob. Revista de las Indias, 12(37), 153.

Medina, Á. (1999). Rómulo Rozo. El arte de su tiempo en América Latina. Rómulo Rozo. Sincretismo. México: Conaculta.

Medina, Á. (2013). La Bachué de Rómulo Rozo en el contexto suramericano. En La Bachué de Rómulo Rozo un icono del arte moderno colombiano (pp. 26-45). Bogotá: Fundación Proyecto Bachué.

Padilla, C. (2013). La Bachué de Rómulo Rozo un icono del arte moderno colombiano. Bogotá: Editorial La Bachué.

Palacios, G. y Covarrubias, A. (2011). Historia de las relaciones internacionales de México. 1821-2010. Vol. 4. América del Sur. México: Secretaría de Relaciones Exteriores.

Picón-Salas, M. (1944). Lo hispanoamericano desde los Estados Unidos. Cuadernos Americanos, 15, 57-66.

Rozo, R. (1956). Monumento a la patria. Mérida: Fondo Editorial Ayuntamiento de Mérida.

Suárez, S. (2016). Una crónica divergente del arte moderno en Colombia: del americanismo a la integración plástica. Revista Credencial Historia, 316, 2-13. Recuperado de http://www.revistacredencial.com/credencial/historia/temas/una-cronica-divergente-del-arte-moderno-en-colombia-del-americanismo-la-integracion

Vallejo, F. (1992). Cartas de Barba Jacob (recopilación y notas de Fernando Vallejo), Bogotá: Revista Literaria Gradiva.

Yankelevich, P. (2003). La revolución mexicana en América Latina. Intereses políticos e itinerarios intelectuales. México: Instituto Mora.

\section{OTRAS FUENTES}

\section{Archivos}

AGNC Archivo General de la Nación-Colombia, Colombia.

AGE-SER Archivo Genaro Estrada, Secretaría de Relaciones Exteriores, México. 


\section{Periódicos}

El Tiempo, 1928-1950.

El Siglo, 2 de agosto de 1937.

Excélsior, 1928-1935.

\section{Bibliografía}

Barba-Jacob, P. (2011). Canción de la vida profunda. Antología. Bogotá: Universidad Externado de Colombia.

Cobo, J. (2004). Lector impenitente. México: FCE.

Vallejo, F. (1997). Barba Jacob el mensajero. Biografía. Bogotá: Editorial Planeta.

Yankelevich, P. (2006). América Latina en la agenda diplomática de la Revolución Mexicana. En J. Schiavon, D. Spenser y M. Vázquez Olivera (eds.). En busca de una nación soberana. Relaciones internacionales de México, siglos XIX y XX (pp. 277-312). México: SRE. 